\title{
Distribution and Nature of Sargassum Species in the Kuwait Waters
}

\author{
Aws Alghunaim, Ali Taqi, Mohammad Al-Kandari, Turki Al-Said \\ Kuwait Institute for Scientific Research, Kuwait City, Kuwait \\ Email: aghunaim@yahoo.com
}

How to cite this paper: Alghunaim, A., Taqi, A., Al-Kandari, M., \& Al-Said, T. (2019). Distribution and Nature of Sargassum Species in the Kuwait Waters. Journal of Geoscience and Environment Protection, 7, 53-59. https://doi.org/10.4236/gep.2019.75006

Received: April 22, 2019

Accepted: May 14, 2019

Published: May 17, 2019

\begin{abstract}
Kuwait coast, which is known for its luxuriant growth of a diverse assemblage of seaweeds on the Arabian Gulf, is found to have abundant quantities of Sargassum species being drifted and washed ashore every year. The present study aimed to assess the quantitative survey, and temporal variations of Sargassum species in Kuwait waters between January to April 2015. Species composition of samples collected from different areas in Kuwait (North, Middle, South waters) reveal that Sargassum algae have localization nature. The most abundant species of Sargassum in Kuwait waters were identified as $S$. anguistifolium, whereas the least abundant species was identified as $\mathcal{S}$. aquifolium. It has been noticed that there is obvious localization nature for some of these species.
\end{abstract}

\section{Keywords}

Sargassum, Kuwait Waters, The Gulf

\section{Introduction}

Sargassum gets its name from the small gas-filled bladders that help keep surface plants afloat. One of the first documented sightings was from Portuguese sailors sailing to the New World. They coined the floating plants salgazo because the round bladders reminded them of a small variety of grapes native to their homeland. Eventually, scientists derived the common name for the genus of brown algae now known as Sargassum. Sargassum is a highly visible macrophytic alga widely distributed in the Kuwait coastal waters represented by $S$. angustifolium, S. oligocystum, S. aquifolium, $S$. boveanum, and S.asperifolium. A quantitative survey of floating Sargassum species during the period January to April 2015 showed three states of Sargassum, i.e., some floating, some washed, and some sedentary with holdfasts. Our investigation reveals that these macroalgae did not 
live very far from where it was originally found floating in the open and offshore waters or washed on the beach.

\section{Materials and Methods}

Offshore and inshore surveys were conducted from January to April 2015, to investigate the brown algae Sargassum species in Kuwait waters. Samples were collected from the north, south, and middle region off Kuwait. Wind and tidal data were followed to determine the high bottom shear stress periods in the study area.

During the survey, a total of around 85qualitative samples of Sargassum samples were collected from different locations of the study area. The study area covered 36 samples from underwater areas, 9 samples from floating locations, and 40 spots covered beaches along the Kuwait coastline. Beach sampling was covering the beaches in the northern areas, middle areas, and southern areas of Kuwait waters. Sargassum samples washed on the beach were collected for qualitative analysis.

According to available identification keys and taxonomic references, we examined the morphological features (the aspect of holdfasts, axes, leaves, vesicles and receptacles) of samples. The morphological characters used for analysis were thallus length, stem, primary and secondary branch, leaf length, width, shape in apex and base, vesicle length, width, pedicle and receptacle shape and length.

\subsection{Study Area}

The survey covered three areas located in the northern waters including the Kuwait Bay, Failaka island, and Ras Al Ardh. The waters in the middle area after Ras Al Ardh including Al Bida, and Fahaheel, and the southern area includes Al-Khiran and Al-Nuwaiseb (Figure 1). Based on the turbidity, salinity, bottom sediments, bathymetry and other physicochemical parameters three naturally different areas can be recognized in Kuwait coastal waters (Al-Yamani et al., 2004). Surveys were conducted focusing on northern Kuwaiti waters in south-west Failaka Island until Salmiya, as well as beaches on the Kuwait Bay. For the middle area, the survey was conducted on the beaches of Al-Fintas until Al-Fahaheel, and for the southern area, Al Khiran was selected for the survey.

\subsection{Sampling}

The coastal marine environment of Kuwait does not exceed $6 \mathrm{~m}$ in depth and can be divided into northern and southern provinces. The northern province, which extends from Ras-Al-Ardh in the south to the northern border of Kuwait, is sheltered, dominated by semi-diurnal tidal action $(3.5 \mathrm{~m})$ and characterized by mudflats. This area is influenced by the outflows of fresh water from Shatt Al-Arab waterway. The southern province, which extends from Ras Al-Ardh to the southern border of Kuwait, is the more open marine environment of higher energy and sandy tidal flats. The tidal range is $<2 \mathrm{~m}$ in the south where diurnal 


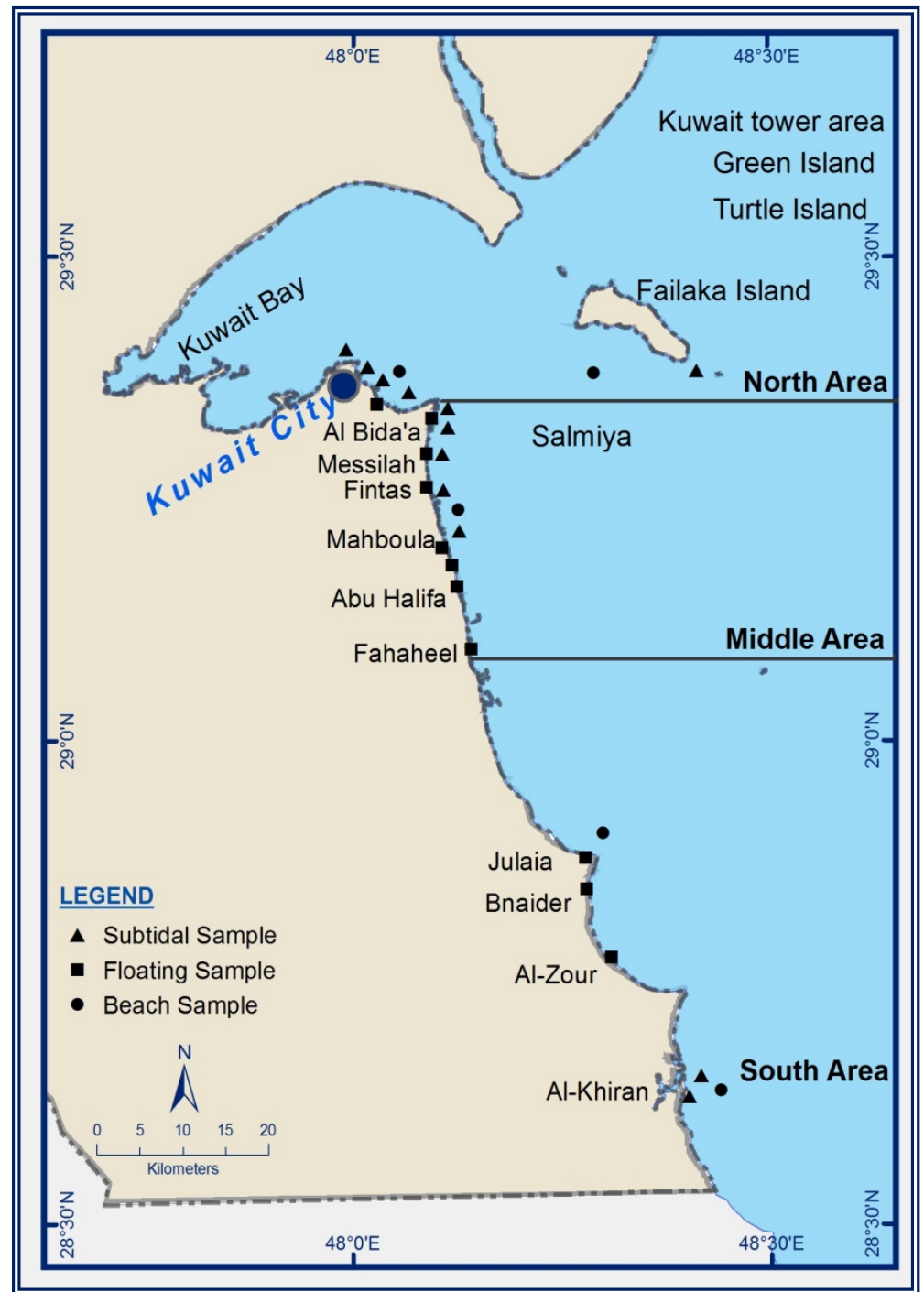

Figure 1. Sampling stations along the Kuwait coast.

tides predominate (Jones, 1986; Al-Hassan \& Jones, 1989; Al-Yamani et al. 2001).

The offshore floating Sargassum species were collected from a speed boat in open waters with a dip net in the vicinity of Failaka Island in the north and Al-Khiran area in the south of Kuwait bay for the qualitative analysis. The floating Sargassum species were estimated by using a GPS support area calculator. For beach sampling, an automobile was used in the northern areas, middle areas, and southern areas for the collection of samples.

Sargassum samples washed on the beach were collected for qualitative analysis. All samples were collected in net bags, tagged with all necessary information, and later transported to seawater tanks at the laboratory facility in order to keep them fresh for processing. In the laboratory, samples were sorted for species composition, biomass measurement, and the presence or absence of holdfasts recorded. 


\subsection{Selecting the Time}

As Sargassum gets detached from the bottom during its life cycle, it is important to determine the approximate period of its existence in the bottom until its dislodgement; ignoring this feature would result in missing an important part of the whole investigation, i.e., the survival period of Sargassum.

\section{Results and Discussion}

Our survey yielded five species of Sargassum i.e. S. angustifolium, S. oligocystum, $S$. aquifolium, $S$. boveanum, and S.asperifolium. The biomass as well as species composition of all the five species of Sargassum as illustrated in Table 1, demonstrates their occurrence in south, middle and northern areas of Kuwait waters. The diversity of the species showed a constant trend from the month of January to April. Although biomass values of Sargassum species varied with the area of collection, the highest biomass values recorded at subtidal for $S$. anguistifolium in the middle areas. Indeed, the most dominant species is represented by $S$. angustifolium, followed by $S$. asperifolium, $S$. boveanum, $S$. oligocystumand, less dominantis appear as $S$. aquifolium. It has been noticed that there is obvious localization nature for some of these species.

Southern Area: Hard substrate extends from the middle to the southern area along the coastline. $S$. asperifolium and $S$. angustifolium were the most abundant species among the floating Sargassum collected from the southern part of the Kuwait waters above oyster beds and hard rocky substrate. Other Sargassum species was found in a very small quantity such as S. aquifolium.

Middle Area: The characteristics of water in this area are closer to waters of the southern area, however, the middle area is more stressed with coastal development. The middle area contains harbors, resorts, marinas, and recreational beaches etc. Although the biomass of macroalgae found in this area is relatively

Table 1. Percentage composition (\%) of Sargassum species collected from subtidal, floating and beaches (washed) of Northern, Middle and Southern areas of Kuwait.

\begin{tabular}{ccccccc}
\hline \multirow{2}{*}{ Source } & S. angustifolium & S. oligocystum & S. aquifolium & S. boveanum & S. asperifolium \\
\cline { 2 - 7 } & $\%$ & $\%$ & $\%$ & $\%$ & $\%$ \\
\hline \multirow{2}{*}{ North } & Subtidal & 55 & 28 & 1 & 17 & 0 \\
& Floating & 46 & 0 & 1 & 54 & 0 \\
& Washed & 40 & 20 & 20 & 0 & 20 \\
\multirow{2}{*}{ Middle } & Subtidal & 91 & 4 & 0 & 1 & 5 \\
& Floating & 35 & 0 & 0 & 48 & 17 \\
& Washed & 37 & 19 & 11 & 26 & 7 \\
& Subtidal & 3 & 0 & 1 & 0 & 96 \\
\multirow{2}{*}{ South } & Floating & 58 & 0 & 1 & 0 & 41 \\
& Washed & 33 & 0 & 33 & 0 & 33 \\
\hline
\end{tabular}


small, among the six species of macroalgae were found washed on beaches located in the middle area between Fahaheel and Fintas, four of them were Sargassum speciesand, $S$. angustifolium was the most abundant species in the middle area. The least abundant species was $S$. asperifolium and was absent in the northern part of the middle area. $S$. boveanumwas found in all the visited beaches, however, their abundance is high in both southern and northern part of the middle area. $S$. oligocystum was the third important species present in the middle area with its absence in the middle area beaches.

Northern Area: S. boveanum was found attached in south-east Failaka island and floating between Failaka and Ras Salmiya. Most of the floating Sargassum collected in this area had holdfasts and occurred during the spring tide. Few $S$. oligocystum were found washed inside turtle island beach of the Kuwait Bay.

According to Bishop et al. (1995), Sargassum in Kuwait detaches themselves from the sea bottom as water temperature warms and then begin to break free of their holdfasts, which agrees with Komatsu et al. (1996) in Japan. Nevertheless, many studies confirmed that Sargassum detached from the sea bottom due to physical disturbances resulting from strong wave action and storms (Rossi et al. 2010; Harries et al. 2007). The natural disintegration of Sargassum after maturation (Gao and Hua 1997) could be a factor associated with minimal physical disturbance to Sargassum detachment.

Studies referred to Sargassum in Kuwait waters are very limited; few unpublished studies suggested to the approximate period of Sargassum existence. So far, it has been reported that Sargassum reaches their maximum growth from March to June (Jones and Al-Attar 1982), coinciding with the growth period of phytoplankton primary production off the Kuwait waters (Al-Yamani et al., 2004). This observation is consistent with the observations made on Sargassum in Hong Kong (Ang, 2006) and Japan (Gao \& Hua, 1997). Therefore, the current study had considered the period from January to April to be a more reliable time for the survey on Sargassum in Kuwait waters, as it falls during the most probable period within the maximum growth of Sargassum and may cover the time of its natural disintegration and detachment.

Species composition of samples collected from different areas in Kuwait (north, middle and, south waters) revealed that Sargassum have localization nature. For example, $S$. asperifolium and $S$. angustifolium are more concentrated in the south; whereas, $S$. boveanum, $S$. anguistifolium, and $S$. oligocystum are the dominant species in the northern area. However, the middle area contains all the species in small quantities, except $S$. angustifolium, which was dominated in the samples. Species such as $S$. oligocystum was found in small quantities in the northern and middle beaches but absent in the southern areas.

\section{Conclusion}

Washed and floating Sargassum in Kuwait are not detached far from its original location and have a localization nature, where different species live in different 
areas with different nature. $S$. anguistifolium dominated all the areas, and $S$. asperifolium monopolize the southern area; whereas, $S$. boveanum command in the north. However, $S$ oligocystum and $S$. aquafolium are represented as minimal in Kuwait waters.

\section{Acknowledgements}

The authors express their sincere gratitude to the diving team for assistance in the field. This work was a part of the research project entitled: "Quantitative survey of Sargassum macroalgae along Kuwait coastline: first step towards its bed restoration". The project was funded by Kuwait Foundation for the Advancement of Sciences under project code: P214-42SL-04.

\section{Conflicts of Interest}

The authors declare no conflicts of interest regarding the publication of this paper.

\section{References}

Al-Yamani, F. Y., Bishop, J., Ramadhan, E., Al-Husaini, M., \& Al-Ghadban, A. N. (2004). Oceanographic Atlas of Kuwait's Waters. Kuwait: Kuwait Institute for Scientific Research.

Al-Yamani, F., Bishop, J., Al-Husaini, M., Al-Ghadban, A., Behbehani, M., Rao, S., Khan, N., Salman, M., Abdel Jawad, M., Al-Attar, M., Al-Rifaie, K., Al-Ghunaim, A., Ismail, W., Lennox, A.W., Lennox, A., \& Al-Tabtibaie, M. (2001). A Strategic Plan for Sustainable Utilization of Kuwait's Marine Environment. Kuwait: KFAS Publication.

Ang Jr., P. O. (2006). Phenology of Sargassum spp. in Tung Ping Chau Marine Park, Hong Kong SAR, China. Journal of Applied Phycology, 18, 629-636. https://doi.org/10.1007/s10811-006-9071-5

Bishop, J. M., Kwartengm, A. Y., Al-Yakoob, S., Abdeli, F., Jacob, P. G., Al-Matouk, K., \& Alsaffar, A.H. (1995). Post-War Survey and Evaluation of Kuwait Shrimp Nursery Grounds with Emphasis on Those South of Kuwait Bay, Phase II. Kuwait: Kuwait Institute for Scientific Research, Report No. KISR4748.

Gao, K., \& Hua, W. (1997). In Situ Growth Rates of Sargassum horneri (Fucales, Phaeophyta). Phycological Research, 45, 55-57.

https://doi.org/10.1111/j.1440-1835.1997.tb00062.x

Harries, D. B., Cook, E., Donnan, D. W., Mair, J. M., Harrow, S., \& Wilson, J. R. (2007). The Establishment of the Invasive Alga Sargassumuticum on the West Coast of Scotland: A Preliminary Assessment of Community Effects. Aquatic Invasions, 2, 367-377. https://doi.org/10.3391/ai.2007.2.4.5

Jones, D. A. (1986). A Field Guide to the Seashores of Kuwait and the Arabian Gulf. Kuwait: University of Kuwait Blanford Press.

Jones, D. A., \& Al-Attar, M. (1982). Observations on the Postlarval and Juvenile Habitats of Penaeus semisulcatus in Kuwait Bay and Adjacent Waters. In C. P. Mathews (Ed.), Revised Proceedings, Shrimp Fisheries Management Workshop, Kuwait Institute for Scientific Research, Report No. 670, Kuwait.

Komatsu, T., Murakami, S., \& Kawai, H. (1996). Some Features of Jump of Water Tem- 
perature in a Sargassum Forest. Journal of Oceanography, 52, 109-124.

https://doi.org/10.1007/BF02236535

Rossi, F., Olabarria, O., Incera, M., \& Garrido, J. (2010). The Trophic Significance of the Invasive Seaweed Sargassum muticum in Sandy Beaches. Journal of Sea Research, 63, 52-61. https://doi.org/10.1016/j.seares.2009.09.005 